\title{
The implementation of the free maternal health policy in rural Northern Ghana: synthesised results and lessons learnt
}

\author{
Philip Ayizem Dalinjong* ${ }^{*}$, Alex Y. Wang and Caroline S. E. Homer
}

\begin{abstract}
Objective: A free maternal health policy was implemented under Ghana's National Health Insurance Scheme to promote the use of maternal health services. Under the policy, women are entitled to free services throughout pregnancy and at childbirth. A mixed methods study involving women, providers and insurance managers was carried out in the Kassena-Nankana municipality of Ghana. It explored the affordability, availability, acceptability and quality of services. In this manuscript, we present synthesised results categorised as facilitators and barriers to access as well as lessons learnt (implications).

Results: Reasonable waiting times, cleanliness of facilities as well as good interpersonal relationships with providers were the facilitators to access. Barriers included out of pocket payments, lack of, or inadequate supply of drugs and commodities, equipment, water, electricity and emergency transport. Four lessons (implications) were identified. Firstly, out of pocket payments persisted. Secondly, the health system was not strengthened before implementing the free maternal health policy. Thirdly, lower level facilities were poorly resourced. Finally, the lack of essential inputs and infrastructure affected quality of care and therefore, access to care. It is suggested that the Government of Ghana, the Health Insurance Scheme and other stakeholders improve the provision of resources to facilities.
\end{abstract}

Keywords: National Health Insurance, Free maternal health policy, Fee exemption, Maternal health services, Pregnancy, Childbirth, Lessons, Ghana

\section{Introduction}

A free maternal health policy was implemented in Ghana in July 2008 under the National Health Insurance Scheme (NHIS). The policy allows all pregnant women to have free registration with the NHIS after which they would be entitled to free services throughout pregnancy, childbirth and 3 months postpartum. The policy was one of Ghana's key strategies for the achievement of the Millennium Development Goals (MDGs) and now, the Sustainable Development Goals (SDGs), specifically the reduction of maternal and child deaths and the achievement of universal health coverage (UHC).

It is unclear whether the policy has achieved its desired outcomes in all parts of Ghana. In other resource

*Correspondence: PhilipAyizem.Dalinjong@student.uts.edu.au Faculty of Health, University of Technology Sydney, Ultimo, Sydney, NSW, Australia constrained settings, it has been shown that there are gaps in similar policy implementation, as these are often implemented without careful planning and inadequate infrastructure as well as resources in terms of workforce and funding [1-3]. Implementation is often affected by factors inside and outside the health system, which ultimately affects access to services.

Access to services is complex and multidimensional [4] and is determined by factors in the health system as well as at the individual, household and community level $[5,6]$. The dimensions of access are classified broadly as affordability, availability, acceptability and quality of care. These affect the use and provision of services and are key for the successful implementation of policies. Therefore, we undertook a study to explore the affordability, availability, acceptability and quality of services under the free maternal health policy. Some of the results have been published in $[7,8]$, specifically 
those relating to affordability. In this manuscript, we present the overall synthesised results in the form of facilitators and barriers to access to services under the free maternal health policy. In addition, we highlight the key lessons (implications) drawn from the study.

\section{Main text \\ Methods}

The study was cross-sectional, combining quantitative and qualitative studies using the convergent parallel mixed methods design. The study area was the Kassena-Nankana municipality in rural Northern Ghana. Quantitative data were collected from women $(\mathrm{n}=406)$ who gave birth in facilities and at home. In-depth interviews were conducted among providers and insurance managers $(n=28)$, while focus group discussions were held with the same category of women $(n=10)$ who participated in the quantitative study. Details of the design, study area, sampling, data collection and analysis are published in $[7,8]$.

\section{Results}

The results have been synthesised and categorised as facilitators and barriers to access in terms of; affordability, availability, acceptability and quality of care. Figure 1 represents the overall synthesised results.

\section{Discussion}

\section{Facilitators of access to services under the policy}

The benefits of the free maternal health policy was widely acknowledged as it promoted the use of services. Other reviews in low- and middle-income settings have reported a significant positive relationship between health insurance including fee exemptions and the use of services $[9,10]$. Interestingly, in our study waiting times were perceived not to impede the use of services. This is contrary to results from studies in Kenya [11], India [12] and Lao People's Democratic Republic [13]. The result may have been because women in this area expected to wait and had very few or limited expectations about what the service would provide.

Equally, we found that the facilities were reported to be clean and providers to be respectful and friendly. The

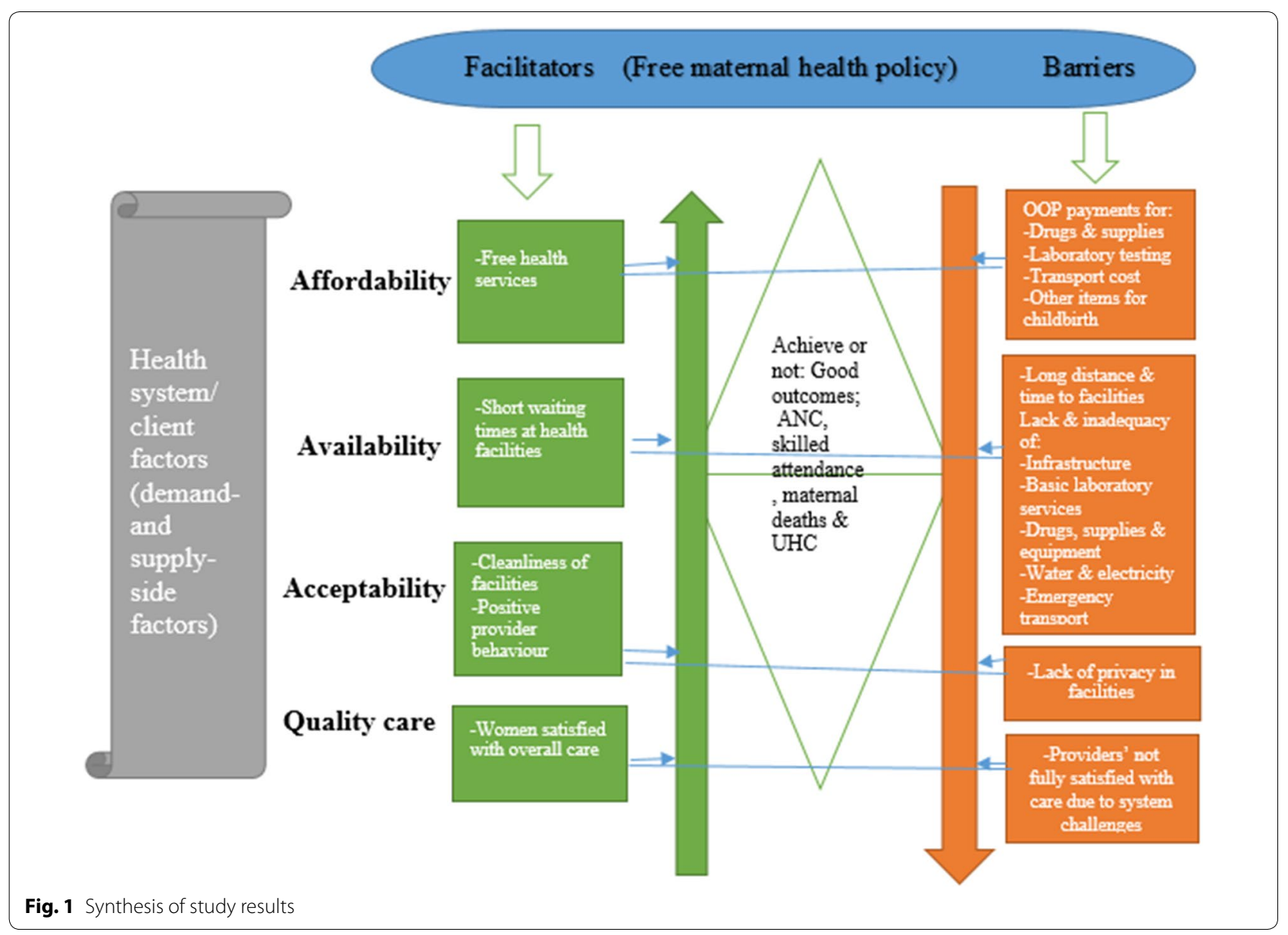


environment of facilities as well as the attitudes of providers are important predictors of service usage. A review on the determinants of women's satisfaction with services in low- and middle-income countries has shown that the interpersonal relationships of providers dominated factors influencing women's use of services [14]. It is encouraging that women in this rural region were positive about their relationships with providers but this may again be attributed to low expectations.

Women interviewed indicated that they were very satisfied or satisfied with quality of care. This result is in line with studies conducted in India and Bangladesh where women were reportedly satisfied with services provided under the Chiranjeevi and the Maternal Health Voucher Schemes respectively $[15,16]$. However, the result runs contrary to other studies, for example from Bangladesh where women expressed dissatisfaction with quality of services received [17]. Satisfaction is a difficult concept and is dependent on expectations and the outcome [18]. For example, many women report being 'satisfied' at the time of care merely because they and their babies survived the experience and sometime later, they articulate a more nuanced, usually negative, experience. This is the halo effect of maternity care [19-21] and may be responsible for our positive results. Despite the high rates of satisfaction, many women in our study also reported a lack of privacy during labour and birth suggesting that perhaps their 'satisfaction' was actually limited.

\section{Barriers for access to services under the policy}

Our study demonstrated that, despite the policy, women still made out of pocket (OOP) payments for drugs, supplies, laboratory services including ultrasound scans and transport as well as the purchase of other items for childbirth. The results corroborate findings from similar settings. For instance, despite a policy in Ethiopia to provide free services for women, $65 \%$ of facilities required women to make payments for some services [22] and in Senegal, where women made payments for transport and drugs under the Free Delivery and Caesarean Policy [23]. These highlight the challenges with implementing fee exemption policies in many countries.

Distance and time taken to reach the nearest facility were perceived in our study to be impediments to care seeking. The result is not isolated. In South Africa and Zambia, women revealed long distances to facilities which hindered access [24, 25]. Likewise, basic essential inputs such as infrastructure, laboratory tests, drugs and supplies, equipment, water, electricity and emergency transport were either inadequate or unavailable in many of the lower level facilities; that is, the community-based health planning and services (CHPS compounds).
While women reported being satisfied with care, this was not the case for the providers. Providers recognised that the situation meant that the care they were providing was sub-standard. Providers often know what 'good' care should be even if their clients are willing to accept less than 'good'. Other studies have highlighted similar issues, for example, in Bangladesh; while women reported satisfaction with services, providers were unhappy with care provision due to staff and logistics challenges, the lack of laboratory services and insufficient supervision [26].

\section{Lessons learnt (implications) from the results}

Although the Government of Ghana has prioritised maternal health by implementing the policy a decade ago, the results of our study raise critical questions about the ability of the policy to meet its goals. Our study highlighted four useful lessons for policy makers and other stakeholders in Ghana. These lessons are relevant to other countries who have implemented or are planning to implement fee free policies.

\section{Lesson number one: OOP payments persisted despite the NHIS}

OOP payments were common. The cost of transport, laboratory services, drugs and supplies made service utilisation difficult especially for poor women. The lack of funds in facilities was a result of the delay in payments by the NHIS, partly caused by the claims process and to some extent the lack of adequate funds for the scheme. The establishment of the electronic claims submission system by the NHIS is a step in the right direction as this will reduce fraud and abuse, help contain costs and promote the financial sustainability of the NHIS $[27,28]$. The system also allows for the early settlement of claims, thereby encouraging them to continue to provide services to clients of the NHIS.

Sustainable sources of funding to ensure funds are available for claims payment within the stipulated time (1 month following submission to the NHIS). Currently, the NHIS relies on a $2.5 \%$ value added tax (Health Insurance Levy) on some categories of goods and services as one of its main sources of funding [29]. An additional 1\% increase in the levy is suggested to raise more money for the smooth operation of the NHIS. The greatest need is to ensure efficiency, as more funding does not necessarily imply the success of the NHIS. Measures should be put in place to identify poor women as a priority for the reimbursement of the cost of transport to facilities, although the process of prioritisation for reimbursement will need attention. Reimbursing the transport cost for women who are poor, in addition to the benefit package of the policy, may encourage their use of services. 
Lesson number two: a weak health system challenged access The inadequacy or unavailability of drugs and supplies, equipment, transport and infrastructure meant the health system was unable to support the successful implementation of the policy. This is synonymous with settings in low- and middle-income countries, where the outbreak of epidemics and other emergencies, for example, the outbreak of the Ebola Virus in West Africa, exposed the vulnerability and weaknesses of the health system [30,31]. Strong health systems are required to attain health goals $[32,33]$, provide routine or usual services and to contain disease outbreaks [34, 35]. Such strong health systems provide the assurance that the required workforce, equipment, drugs and supplies, transport, information, monitoring and supervision, affordable and responsive services as well as good provider relations exist in the process of service delivery [36]. The success of Ghana's policy requires an ongoing investment in drugs and supplies, equipment and transport as well as improvement in the infrastructure of facilities.

\section{Lesson number three: lower level facilities are poorly resourced}

Lower level facilities (CHPS compounds) in the study are poorly resourced for the provision of services to people living in distant and remote communities. Nevertheless, these play a crucial role, acting as gatekeepers to the health system and as the first point of care for women, including the poor. These facilities also provide basic preventive and curative services. Thus, strengthening peripheral health systems is key to the achievement of good health outcomes as well as the attainment of UHC. Our study highlights the need for an expansion in the infrastructure of the CHPS compounds, including the provision of emergency transport at the community level, as well as the provision of water and electricity in the facilities.

Water and electricity are crucial for the effective operation of facilities. Water helps maintain hygiene and sanitation in facilities, while electricity facilitates the sterilisation of equipment as well as storage of drugs, vaccines and associated adjuvants [37, 38]. The World Health Organization (WHO) considers WASH (Water, Sanitation and Hygiene) services in facilities as very necessary for the attainment of the SDGs, especially those relating to maternal and child health [39]. This explains the inclusion of WASH services in the framework for quality of care for maternal and child health.

\section{Lesson number four: lack of essential inputs} and infrastructure impeded quality care

Quality of care is compromised by the lack of essential inputs and infrastructure in facilities. Poor quality of care not only discourages women from service usage, but does not permit the achievement of good health outcomes. For instance, implementing fee free policies may lead to an increase in the use of services but maternal deaths may not reduce proportionately if the quality of care is poor [10]. All pregnant women need to be provided with quality care at pregnancy, labour, birth and beyond [40, 41]. The WHO's framework for quality of care stipulates the need for continuous assessment, improvement and monitoring within the health system. It is crucial to ensure the availability of the necessary inputs for quality care provision [41], including an adequate workforce and skilled, regulated and educated midwives [42].

In conclusion, lessons from our study included the persistence of OOP payments, a vulnerable health system, poorly resourced lower level facilities and low quality of care due to the lack of essential inputs and infrastructure. These negatively affect the drive towards reducing maternal and child deaths and the attainment of UHC. It is suggested that the Government of Ghana, the NHIS and other stakeholders improve the provision of resources to facilities, especially lower level ones.

\section{Limitations of the study}

The study has its limitations. Firstly, the estimated levels of OOP payments might be underestimated, as productivity losses for women and their caregivers were not determined. Secondly, recall bias on the part of the women cannot be ruled out since the interviews and discussions were held after women had given birth.

\footnotetext{
Abbreviations

CHPS: community-based health planning and services; MDGs: Millennium Development Goals; NHIS: National Health Insurance Scheme; OOP: out of pocket; UHC: universal health coverage; SDGs: Sustainable Development

Authors' contributions PAD carried out the data analysis. PAD wrote the manuscript and AYW and

\author{
Acknowledgements \\ We thank all participants for their participation in the study. \\ Competing interests \\ The authors declare that they have no competing interests.
} Goals; WASH: Water, Sanitation and Hygiene; WHO: World Health Organization.

PAD AYW CSEH conceived and conceptualized the study. PAD collected data. CSEH critically reviewed it. All authors read and approved the final manuscript. 


\section{Availability of data and materials}

The dataset supporting the conclusions of this article is included within the article.

\section{Consent for publication}

Not applicable.

\section{Ethics approval and consent to participate}

The Ethical Review Board of the Navrongo Health Research Centre, Ghana (NHRCIRB217) and the Human Research Ethics Committee of the relevant university (ETH16-0263) gave approval to carry out the study. All participants gave written consent to participate in the study.

\section{Funding}

The University of Technology Sydney (UTS) awarded two scholarships (UTS International Research Scholarship and UTS President's Scholarship) to enable the first author pursue a doctoral degree in UTS. UTS WHO Collaborating Centre in Nursing, Midwifery and Health also provided a travel award for data collection of the PhD project.

\section{Publisher's Note}

Springer Nature remains neutral with regard to jurisdictional claims in published maps and institutional affiliations.

\section{Received: 16 April 2018 Accepted: 24 May 2018}

Published online: 29 May 2018

\section{References}

1. Banchani E, Tenkorang E. Implementation challenges of maternal health care in Ghana: the case of health care providers in the Tamale Metropolis. BMC Health Serv Res. 2014;14(1):7. https://doi. org/10.1186/1472-6963-14-7.

2. Puchalski RLM, Khan S, Moore JE, Timmings $C$, van Lettow M, Vogel JP, et al. Low- and middle-income countries face many common barriers to implementation of maternal health evidence products. J Clin Epidemiol. 2016;76(Supplement C):229-37. https://doi.org/10.1016/j.jclin epi.2016.02.017

3. Erasmus E, Orgill M, Schneider H, Gilson L. Mapping the existing body of health policy implementation research in lower income settings: what is covered and what are the gaps? Health Policy Plan 2014;29(suppl_3):iii35-50.https://doi.org/10.1093/heapol/czu063.

4. Gulliford M, Figueroa-Munoz J, Morgan M, Hughes D, Gibson B, Beech $\mathrm{R}$, et al. What does 'access to health care' mean? J Health Serv Res Policy. 2002:7(3):186-8. https://doi.org/10.1258/135581902760082517.

5. Hunter DJ, Killoran A. Tackling health inequalities: turning policy into practice?. London: Health Development Agency; 2004.

6. Jacobs B, Ir P, Bigdeli M, Annear PL, Damme WV. Addressing access barriers to health services: an analytical framework for selecting appropriate interventions in low-income Asian countries. Health Policy Plann. 2012;27(4):288-300

7. Dalinjong PA, Wang AY, Homer CSE. The operations of the free maternal care policy and out of pocket payments during childbirth in rural Northern Ghana. Health Econ Rev. 2017;7(1):41. https://doi.org/10.1186/s1356 1-017-0180-4.

8. Dalinjong PA, Wang AY, Homer CSE. Has the free maternal health policy eliminated out of pocket payments for maternal health services? Views of women, health providers and insurance managers in Northern Ghana. PLoS ONE. 2018;13(2):e0184830. https://doi.org/10.1371/journ al.pone. 0184830 .

9. Comfort AB, Peterson LA, Hatt LE. Effect of health insurance on the use and provision of maternal health services and maternal and neonatal health outcomes: a systematic review. J Health Popul Nutr. 2013;31(4 Suppl 2):S81-105

10. Hatt LE, Makinen M, Madhavan S, Conlon CM. Effects of user fee exemptions on the provision and use of maternal health services: a review of literature. J Health Popul Nutr. 2013;31(4 Suppl 2):S67-80.

11. Mason L, Dellicour S, Ter Kuile F, Ouma P, Phillips-Howard P, Were F, et al. Barriers and facilitators to antenatal and delivery care in western Kenya: a qualitative study. BMC Pregnancy Childbirth. 2015;15(1):26. https://doi. org/10.1186/s12884-015-0453-z.

12. Patel $R$, Ladusingh $L$. Do physical proximity and availability of adequate infrastructure at public health facility increase institutional delivery? A three level hierarchical model approach. PLoS ONE. 2015;10(12):e0144352. https://doi.org/10.1371/journal.pone.0144352.

13. Ngan DK, Kang M, Lee C, Vanphanom S. "Back to Basics" approach for improving maternal health care services utilization in Lao PDR. Asia Pac J Public Health. 2016;28(3):244-52. https://doi.org/10.1177/1010539516 634188.

14. Srivastava A, Avan BI, Rajbangshi P, Bhattacharyya S. Determinants of women's satisfaction with maternal health care: a review of literature from developing countries. BMC Pregnancy Childbirth. 2015;15:97. https ://doi.org/10.1186/s12884-015-0525-0.

15. Ahmed S, Khan MM. A maternal health voucher scheme: what have we learned from the demand-side financing scheme in Bangladesh? Health Policy Plan. 2011;26(1):25-32. https://doi.org/10.1093/heapol/czq015.

16. Bhat R, Mavalankar DV, Singh PV, Singh N. Maternal healthcare financing: Gujarat's Chiranjeevi scheme and its beneficiaries. J Health Popul Nutr. 2009;27(2):249-58.

17. Chowdhury S, Hossain SA, Halim A. Assessment of quality of care in maternal and newborn health services available in public health care facilities in Bangladesh. Bangladesh Med Res Counc Bull. 2009;35(2):53-6.

18. van Teijlingen ER, Hundley V, Rennie AM, Graham W, Fitzmaurice A. Maternity satisfaction studies and their limitations: "What is, must still be best". Birth. 2003;30(2):75-82

19. Jha P, Larsson M, Christensson K, Skoog Svanberg A. Satisfaction with childbirth services provided in public health facilities: results from a cross- sectional survey among postnatal women in Chhattisgarh, India. Global Health Action. 2017;10(1):1386932. https://doi.org/10.1080/16549 716.2017 .1386932$.

20. Bennett A. The birth of a first child: do women's reports change over time? Birth. 1985;12(3):153-8.

21. Waldenstrom U. Women's memory of childbirth at two months and one year after the birth. Birth. 2003;30(4):248-54.

22. Pearson L, Gandhi M, Admasu K, Keyes EB. User fees and maternity services in Ethiopia. Int J Gynaecol Obstet. 2011;115(3):310-5. https://doi. org/10.1016/j.ijgo.2011.09.007.

23. Witter S, Drame FB, Cross S. Maternal fee exemption in Senegal: is the policy a success? Afr J Midwifery Women's Health. 2009;3(1):5-10. https:// doi.org/10.12968/ajmw.2009.3.1.39409.

24. Silal SP, Penn-Kekana L, Harris B, Birch S, Mclntyre D. Exploring inequalities in access to and use of maternal health services in South Africa. BMC Health Serv Res. 2012;12:120. https://doi.org/10.1186/1472-6963-12-120.

25. Stekelenburg J, Kyanamina S, Mukelabai M, Wolffers I, van Roosmalen J. Waiting too long: low use of maternal health services in Kalabo, Zambia. Trop Med Int Health. 2004;9(3):390-8. https://doi.org/10.111 1/j.1365-3156.2004.01202.x.

26. Islam F, Rahman A, Halim A, Eriksson C, Rahman F, Dalal K. Perceptions of health care providers and patients on quality of care in maternal and neonatal health in fourteen Bangladesh government healthcare facilities: a mixed-method study. BMC Health Serv Res. 2015;15(1):237. https://doi. org/10.1186/s12913-015-0918-9.

27. Park YT, Yoon JS, Speedie SM, Yoon H, Lee J. Health insurance claim review using information technologies. Healthcare Inform Res. 2012;18(3):21524. https://doi.org/10.4258/hir.2012.18.3.215.

28. Nsiah-Boateng E, Asenso-Boadi F, Dsane-Selby L, Andoh-Adjei FX, Otoo $\mathrm{N}$, Akweongo P, et al. Reducing medical claims cost to Ghana's National Health Insurance scheme: a cross-sectional comparative assessment of the paper- and electronic-based claims reviews. BMC Health Serv Res. 2017;17(1):115. https://doi.org/10.1186/s12913-017-2054-1.

29. NHIA. Annual report 2009. Accra: National Health Insurance Authority, Ghana; 2010

30. Bitton A, Ratcliffe HL, Veillard JH, Kress DH, Barkley S, Kimball M, et al. Primary health care as a foundation for strengthening health systems in low- and middle-income countries. J Gen Intern Med. 2017;32(5):566-71. https://doi.org/10.1007/s11606-016-3898-5.

31. Borghi J, Chalabi Z. Square peg in a round hole: re-thinking our approach to evaluating health system strengthening in low-income and middleincome countries. BMJ Global Health. 2017;2(3):e000406. 
32. Van Lerberghe W, Matthews Z, Achadi E, Ancona C, Campbell J, Channon $A$, et al. Country experience with strengthening of health systems and deployment of midwives in countries with high maternal mortality. Lancet. 2014;384(9949):1215-25. https://doi.org/10.1016/S0140 -6736(14)60919-3.

33. Mills A. Health care systems in low- and middle-income countries. N Engl J Med. 2014:370(6):552-7. https://doi.org/10.1056/NEJMra1110897.

34. Cancedda C, Davis SM, Dierberg KL, Lascher J, Kelly JD, Barrie MB, et al. Strengthening health systems while responding to a health crisis: lessons learned by a nongovernmental organization during the ebola virus disease epidemic in Sierra Leone. J Infect Dis. 2016;214(suppl_3):S153-63. https://doi.org/10.1093/infdis/jiw345.

35. Regmi K, Gilbert R, Thunhurst C. How can health systems be strengthened to control and prevent an Ebola outbreak? A narrative review. Infect Ecol Epidemiol. 2015;5:28877. https://doi.org/10.3402/iee.v5.28877.

36. WHO. Monitoring the building blocks of health systems: a handbook of indicators and their measurement strategies. Geneva: World Health Organization; 2010.

37. WHO. Access to modern energy services for health facilities in resourceconstrained settings: a review of status, significance, challenges and measurement. Geneva: World Health Organization; 2015.
38. Essendi H, Johnson FA, Madise N, Matthews Z, Falkingham J, Bahaj AS, et al. Infrastructural challenges to better health in maternity facilities in rural Kenya: community and healthworker perceptions. Reprod Health. 2015;12:103. https://doi.org/10.1186/s12978-015-0078-8.

39. WHO. Water and sanitation for health facility improvement tool (WASH FIT). Geneva: World Health Organization; 2017

40. WHO. Standards for improving quality of maternal and newborn care in health facilities. Geneva: World Health Organization; 2016.

41. Hulton L, Matthews Z, Bandali S, Izge A, Daroda R, Stones W. Accountability for quality of care: Monitoring all aspects of quality across a framework adapted for action. Int J Gynaecol Obstet. 2016;132(1):110-6. https://doi. org/10.1016/j.ijgo.2015.11.005.

42. Renfrew MJ, McFadden A, Bastos MH, Campbell J, Channon AA, Cheung $N F$, et al. Midwifery and quality care: findings from a new evidence-informed framework for maternal and newborn care. Lancet. 2014;384(9948):1129-45. https://doi.org/10.1016/S0140-6736(14)60789 $-3$
Ready to submit your research? Choose BMC and benefit from:

- fast, convenient online submission

- thorough peer review by experienced researchers in your field

- rapid publication on acceptance

- support for research data, including large and complex data types

- gold Open Access which fosters wider collaboration and increased citations

- maximum visibility for your research: over $100 \mathrm{M}$ website views per year

At BMC, research is always in progress.

Learn more biomedcentral.com/submissions 